
\title{
R Research S Surare \\ Fretting Wear Mechanical Analysis of Double Rough Surfaces Based on Energy Method
}

\section{Ling Li ( $\nabla$ liling@xauat.edu.cn )}

Xi'an University of Architecture and Technology

\section{Ganghua Li}

Xi'an University of Architecture and Technology

\section{JingJjing Wang}

Xi'an University of Architecture and Technology

\section{Xiaohui Shi}

Xi'an University of Architecture and Technology

\section{Anjiang Cai}

Xi'an University of Architecture and Technology

\section{Original Article}

Keywords: Fretting wear, Rough surface, Surface roughness, Material rigidity, Coefficient of friction

Posted Date: September 15th, 2021

DOI: https://doi.org/10.21203/rs.3.rs-882627/v1

License: (c) (1) This work is licensed under a Creative Commons Attribution 4.0 International License. Read Full License 


\section{Title page}

\section{Fretting wear mechanical analysis of double rough surfaces based on energy method}

Ling Li, born in 1981, is currently a professor and a PhD candidate supervisor at School of Mechanical and Electrical Engineering, Xi'an University of Architecture and Technology, China. He received his $\mathrm{PhD}$ degree from Beijing University Of Technology, China, in 2012. His research interests include mechanical dynamics, contact mechanics and tribology.

Tel: +86-15389062450; E-mail: liling@ xauat.edu.cn

Gang-Hua Li, born in 1997, is currently a master candidate at School of Mechanical and Electrical Engineering, Xi'an University of Architecture and Technology, China.

E-mail: ganghuali@163.com

Jing-Jing Wang, born in 1996, is currently a PhD candidate at School of Mechanical and Electrical Engineering, Xi'an University of Architecture and Technology, China. He received his master degree from Xi'an University of Architecture and Technology, China, in 2021. His research interests include microscopic interface contact mechanics.

E-mail: lee_wjj@163.com

Xiao-Hui Shi, born in 1977, is currently a lecturer at Xi'an University of Architecture and Technology, China. He received his PhD degree from Xi'an University of Architecture and Technology, China, in 2006. His research interests include smart city transportation planning, design and system integration.

E-mail: 13811382617@163.com

An-Jiang Cai, born in 1965, is currently a professor and a $\mathrm{PhD}$ candidate supervisor at School of Mechanical and Electrical Engineering, Xi'an University of Architecture and Technology, China. He received his master degree from Xi'an University of Architecture and Technology, China, in 2002. His main research interests include mechanical transmission, machinemry manufacturing technology and precision machining technology.

E-mail: Cai_aj@163.com

\section{Corresponding author: Ling Li E-mail: liling@xauat.edu.cn}




\title{
Fretting wear mechanical analysis of double rough surfaces based on energy method
}

\author{
Ling $\mathrm{Li}^{1}{ }^{1}$ Gang-Hua $\mathrm{Li}^{1} \cdot$ Jing-Jing Wang ${ }^{1} \cdot \mathrm{Xiao}^{-H u i} \mathrm{Shi}^{1} \cdot$ An-Jiang Cai ${ }^{1}$
}

Received June xx, 201x; revised February xx, 201x; accepted March xx, 201x

(c) Chinese Mechanical Engineering Society and Springer-Verlag Berlin Heidelberg 2017

\begin{abstract}
A fretting wear model of rough surface that conforms to the actual situation is established to accurately reveal the wear mechanism of the connection structure. In the ABAQUS software, the UMESHMOTION subroutine and the energy dissipation model are used to simulate the fretting wear of double rough surfaces. The new model, a single rough surface model, and a smooth model are compared to analyze the differences between them. In addition, the influence of surface roughness, material, and friction coefficient on the fretting wear of rough surfaces is systematically explored through finite element simulation. The results show that the reliability of the model has been verified through Hertz's theory and experiments. The stress and wear of the contact surface are more realistically reflected by the double roughness model. Besides, with the increase of surface roughness and material rigidity and the decrease of friction coefficient, the wear of the double rough surface model becomes more severe. The research work provides a theoretical basis for the design and performance prediction of the connection structure.
\end{abstract}

Keywords: Fretting wear - Rough surface - Surface roughness • Material rigidity $\bullet$ Coefficient of friction

\section{Introduction}

Mechanical equipment is widely used in practical projects like transportation, power transmission equipment, bridge engineering, navigation, and aerospace. They are usually assembled by several parts in different ways, such as bearings, bolts, rivet connections and spline fits, etc. [1]. Fretting is a small amplitude (less than $100 \mu \mathrm{m}$, generally

Ling Li

liling@xauat.edu.cn

1 School of Mechanical and Electrical Engineering, Xi'an University of Architecture and Technology, Xi'an 710055, China
2 20 $\mu \mathrm{m}$ ) reciprocating motion between two contact surfaces caused by vibration, which usually occurs in these seemingly close-fitting mechanical connections. The fretting can cause various negative influences, such as friction and wear between the contact surfaces, initiation and propagation of cracks, and seizure and loosening of the components, which all seriously reduce the fatigue life of the components $[2,3]$. Fretting wear has become the main cause of failure for connection parts. Therefore, understanding the fretting wear mechanism of the connecting structure is extremely important.

At present, experimental testing and finite element simulation are two main methods to study the phenomenon of fretting wear [4]. Compared with the experimental method, the finite element simulation can produce a much more detailed set of results, and it is very convenient and time-saving, suiting to explore the potential mechanism of fretting wear. As the first numerical model, the Archard model gives the relationship between the amount of wear and the relative slip distance [5]. Then, this model is used in finite element simulation and verified by experimental data in Mccoll et al. [6]. Subsequently, the finite element model was extended to more general problems in fretting wear. For example, an optimized finite element model which gives more accurate results of fretting wear was established by Madge et al. [7], where the UMESHMOTION subroutine and ALE adaptive mesh technology in ABAQUS are used. Kasarekar et al. [8] pointed out that surface roughness is a non-negligible factor when calculating wear and proposed a model considering the effect of surface roughness on the evolution of wear under partial slip. Considering the influence of surface roughness on fretting wear under complete sliding conditions, Leonard et al. [9] found that 
the influence of roughness is only significant at the beginning of the experiment. Shen et al. [10] combined the Archard model and a discrete quasi-static model to analyze the dynamic wear process of bearings, where complex nonlinear wear processes were captured. Tang et al. [11] established a two-dimensional cylindrical/planar contact finite element model to study the fretting wear behavior of zirconium alloys. They found that the wear characteristics under partial sliding and full sliding conditions are inconsistent.

The Archard model has a limitation that the influence of the friction coefficient on the wear rate under the alternating sliding state [12] is not considered. To resolve this issue, a wear calculation model based on energy dissipation was proposed by Fouvry and Sauger et al. [13, 14], where the relationship between wear volume and accumulated dissipated energy is determined by the energy wear coefficient. In addition, experimental studies have shown that the energy dissipation method is superior to the Archard method [15, 16]. Paulin et al. [17] developed a finite element model based on an energy equation verified by experimental results. After that, the energy method is applied to practical problems. Ming et al. [18] developed a finite element model considering local deformation of the thread surface to simulate the self-loosening phenomenon of bolts under lateral loads. Jiang et al. [19] studied the electrical contact durability and electromagnetic induction failure under fretting wear. The surface roughness has a great influence on the wear, fatigue, temperature rise [20-24], and friction characteristics [25] of the connecting structure. However, the effect of roughness is not considered in most finite element models [4, 16, 17, 26]. To study temperature rise distribution in fretting contact, Qin et al. [27] employed the Weierstrass-Mandelbrot function (W-M function) to approximate rough contact surface. In their finite element model, the two rough surfaces are characterized by a rigid smooth plane and an equivalent rough surface. Pereira et al. [28] developed a multi-scale method to study the effect of roughness on fretting wear, but the rough contact surface is replaced by a smooth surface. None of the above studies considered the two surfaces which are rough, and thus cannot accurately reveal the actual fretting wear mechanism.

In this paper, a finite element model of fretting wear considering two rough contact surfaces is developed. The fractal curve generated by the $\mathrm{W}-\mathrm{M}$ function is used to simulate the rough contact surface. The dynamic simulation of fretting wear is realized through the energy dissipation model and the UMESHMOTION subroutine. The difference between the rough model, the smooth model, and the single rough surface model is analyzed through comparison. The significant factors that may affect the fretting wear are systematically investigated, including the roughness, material properties, and friction coefficient.

\section{Fretting wear modeling on rough surfaces}

\subsection{Characterization of surface topography}

The fractal theory has been found useful to characterize rough surfaces because the contour curves of rough surfaces have self-similarity [29]. The curve generated by the W-M function has the characteristics of continuous and non-differentiation, and its expression is given as [30, 31]

$$
Z(x)=G^{(D-1)} \sum_{n=n_{1}}^{\infty} \gamma^{-(2-D) n} \cos \left(2 \pi \gamma^{n} x\right),
$$

where $Z(x)$ is the height of the curve, $x$ is the corresponding coordinate, $G$ is the characteristic scale coefficient, $D$ is the fractal dimension $(1<D<2), \gamma$ is a fixed value larger than 1 (usually 1.5), $n$ is a spatial frequency coefficient, $\gamma^{n}$ is the spatial frequency which is equal to the inverse of the surface wavelength $\left(\gamma^{n}=1 / \lambda_{n}\right)$, and $n_{1}$ is an ordinal number corresponding to the lowest cut-off frequency which is related to the sampling length $L$, $\gamma^{n}{ }_{1}=1 / L$.

For the case $L=0.6 \mathrm{~mm}$ and $\gamma=1.5$ and the characteristic scale factor $G=4.35 \times 10^{-12} \mathrm{~m}$, the fractal curve is shown in Fig. 1. Then, the surface roughness $R a$ corresponding to the fractal dimension is obtained by substituting the curve value into equation (2) [32]. The calculated results of surface roughness $R a$ are $0.8 \mu \mathrm{m}, 0.5 \mu \mathrm{m}$, and $0.2 \mu \mathrm{m}$ when the fractal dimension $D$ is $1.52,1.57$, and 1.67.

$$
R a=\frac{1}{L} \int_{0}^{L}|Z(x)| d x
$$
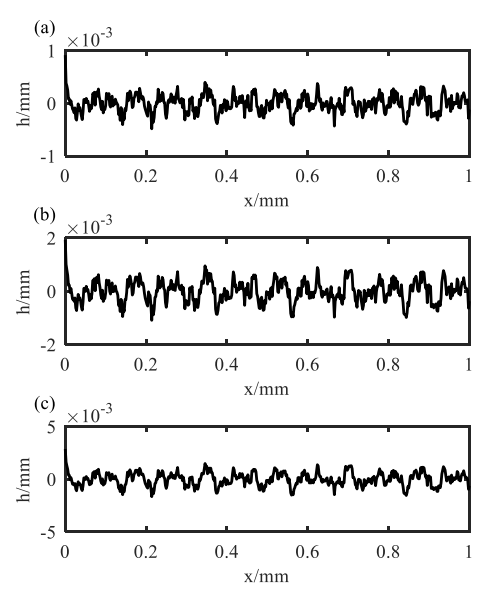
Figure 1 Surface profile curves with different fractal dimensions

\subsection{Finite element software modeling}

The sample is composed of a semi-cylindrical body with a radius of $6 \mathrm{~mm}$ and a flat with a width of $12 \mathrm{~mm}[33,34]$, as shown in Fig. 2(a). Table 1 shows the material parameters set by the finite element model. Among them, the material of the semi-cylindrical body is alloy steel, ductile iron (QT800-2), or gray cast iron (HT200), and the material of the flat is alloy steel [35]. The radius of the semi-cylindrical body is $R=6 \mathrm{~mm}$, and the length and width of the flat are $12 \mathrm{~mm}$ and $6 \mathrm{~mm}$, respectively. At the contact center area of the upper and lower specimens,

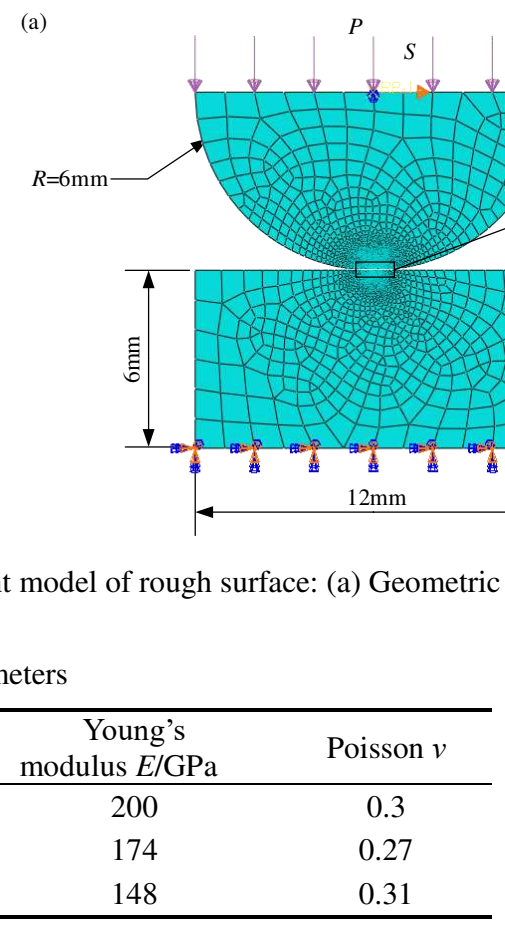

Before performing mechanical analysis on the model, meshing is first required. A four-node plane strain element (CPE4) is used to discretize the model [36]. It is particularly important to note that to accurately obtain the contact data, the mesh of the rough contact area needs to be refined. The mesh near the rough contact area is refined with a size of about $1.5 \mu \mathrm{m} \times 1.5 \mu \mathrm{m}$. In addition, the setting of contact attributes and interactions in finite element simulation is also very important. In the contact properties, the tangential behavior is set to isotropic Coulomb friction. Lagrange multipliers are used to define tangential constraints. The hard contact method is used to define the normal behavior of the contact pair. The master-slave interaction algorithm is adopted by contact discretization in the rough finite element model. Among them, the lower rough contour curves are introduced separately to form two rough surfaces in contact, as shown in Fig. 2(b). The length of the rough profile curve is $0.4 \mathrm{~mm}$. The rough contour curve is fitted by using a Python script to import the coordinate values of the curve in Fig. 1 into the ABAQUS software. Fig. 2(c) shows the loading history of the model, which can be divided into two stages. The normal uniform load $P$ with a magnitude of $20 \mathrm{MPa}$ is applied in step 1 and remains unchanged in the subsequent analysis steps. A periodic tangential displacement with an amplitude of 3 $\mu \mathrm{m}$ is applied in step 2 and circulates five times in a complete analysis step. We use static general analysis steps in all the models.

(b)

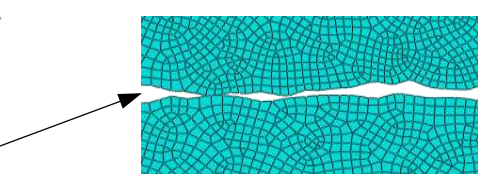

(c)

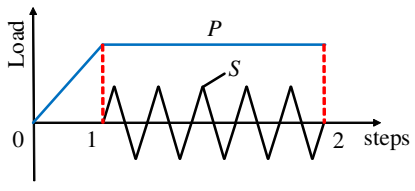

Figure 2 Finite element model of rough surface: (a) Geometric model (b) Local details of contact area (c) Loading history surface of the semi-cylindrical body is defined as master, and the top surface of the flat is defined as slave.

In the force analysis process in Fig. 2, the bottom of the flat is fully constrained. The normal load $\mathrm{P}$ is applied on the top surface of the semi-cylindrical body to bring the two rough surfaces into contact. A reference point is set at the center of the top surface of the semi-cylindrical body. The reference point and the top surface are bound together through the multi-point constraint (MPC). Periodic horizontal displacement is applied at the reference point to make the two parts slide relative.

\subsection{Calculation of fretting wear}

The prerequisite for accurate calculation of fretting wear is to obtain a suitable numerical model. The Archard model is a classic wear calculation model, but it is not applicable when the friction coefficient is not a fixed value, or the surface is partially slipped. For this reason, in the finite element simulation, the energy dissipation model is used to calculate fretting wear reasonable. According to the energy dissipation model [4], the amount of wear is proportional to the energy consumed between the surfaces, which can be defined as 


$$
\begin{gathered}
V=\alpha E_{\mathrm{d}}, \\
E_{\mathrm{d}}=\int Q \mathrm{~d} S,
\end{gathered}
$$

where $V$ is the wear volume, $\alpha$ is the wear coefficient, $E_{\mathrm{d}}$ is the energy consumed by wear, $Q$ is the friction shear force, and $S$ is the displacement amplitude of the sample.

By using the shear stress of each node to replace the total friction force, the wear depth at each node is calculated separately. In the process of a complete cyclic load, the wear depth at $x$ is

$$
h(x)=\sum_{i=1}^{T} \alpha q(x)_{i} \Delta s(x)_{i},
$$

where $h(x)$ is the wear depth, $q(x)_{i}$ is the shear force at the position $x$ of the $i$ incremental step, $\Delta s(x)_{i}$ is the relative slip distance at the location $x$ in the $i$ incremental step, and $T$ is the number of incremental steps.

In the simulation of fretting wear, the amount of wear generated in one cycle is very small. Therefore, one incremental step is used to instead of the cyclic load of $\Delta N$ times. This not only ensures accuracy but also reduces simulation time. The acceleration of the wear simulation is realized. After acceleration, the wear depth at the location $x$ is expressed as

$$
h(x)=\Delta N \sum_{i=1}^{T} \alpha q(x)_{i} \Delta s(x)_{i},
$$

The number of accelerations $\Delta N$ used in the model is 1000 [18], and the wear coefficient $\alpha$ is $3.33 \times 10^{-8} \mathrm{MPa}^{-1}$ [4].

In addition, variation of the surface profile leads to the change of the nodal stress and strain, which will affect the accuracy of the final simulation results. For this reason, the grid near the rough surface was set as an adaptive grid (ALE) to make it automatically adjust. The UMESHMOTION subroutine is called at the end of each incremental step to obtain data and calculate the amount of wear. At the same time, the grid nodes are updated. Therefore, the accuracy of wear is guaranteed by keeping the mesh in a proper shape at all times.

\section{Validation of the model}

We then validate the established model by comparing the results of finite element simulation with the cylinder/plane wear test [6]. Here, for facilitating verification, surface roughness is not considered. The material used in the literature is high-strength alloy steel, and the material parameters are the same as the model in this paper. The mesh size of the contact area is $10 \mu \mathrm{m}$, the friction coefficient is 0.8 , the amplitude of the displacement load is $S=25 \mu \mathrm{m}$, the normal load is $F=185 \mathrm{~N}$, and the other parameters are consistent with the previous ones.

Before verifying the wear model, the accuracy of the model before wear should be guaranteed first. The contact pressure at the end of step 1 was obtained. The correctness of the model before wear was verified by comparing with the analytical solution of the Hertzian stress distribution. Under a normal load $F$, the Hertzian contact half-width $a$ is given as [19]

$$
a=\sqrt{\frac{4 F R}{\pi E^{*}}},
$$

and the stress distribution is expressed as

$$
P(x)=P_{0} \sqrt{1-\frac{x^{2}}{a^{2}}},
$$

where $\quad E^{*}=\left[\left(1-\mu_{1}\right) / E_{1}+\left(1-\mu_{2}\right) / E_{2}\right]^{-1}, \quad R=\left(1 / R_{1}+1 / R_{2}\right)^{-1}$, $P_{0}=\left[F E^{*} /(\pi R)\right]^{1 / 2}, E_{1}$ and $E_{2}$ represent the elastic modulus of the two materials, $\mu_{1}$ and $\mu_{2}$ represent the Poisson's ratio of the two materials, and $R_{1}$ and $R_{2}$ represent the radius of curvature of the contact surface of the two samples. For the cylinder/plane contact type, we take the radius of curvature $R_{2}$ of the plane to be infinite in the above formula.

Fig. 3(a) shows the comparison between the finite element results and the Hertz theory. It can be seen that the finite element results are consistent with the theoretical calculation, which verifies the accuracy of the model without the wear effect. Finite element results on both sides of the contact area slightly deviate from the transverse coordinates of the Hertz model, which is caused by the grid size not being small enough.

The wear depth after 18,000 cycles is compared with the experimental data in the literature, as shown in Fig. 3(b). The wear width and maximum wear depth of the finite element model are consistent with the experimental results. The same UMESHMOTION subroutine and finite element model are used in the model with a rough surface and the previous verification model. Therefore, the rough model of fretting wear is reliable. From the finite element results, it can also be found that the contour of the contact surface after wear is smooth, which is different from the actual situation. The important effect of rough surfaces on fretting wear has been emphasized again. 
(a)

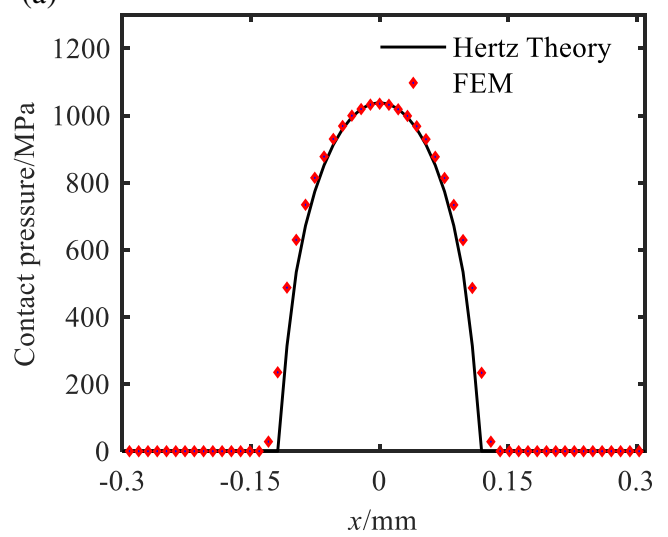

(b)

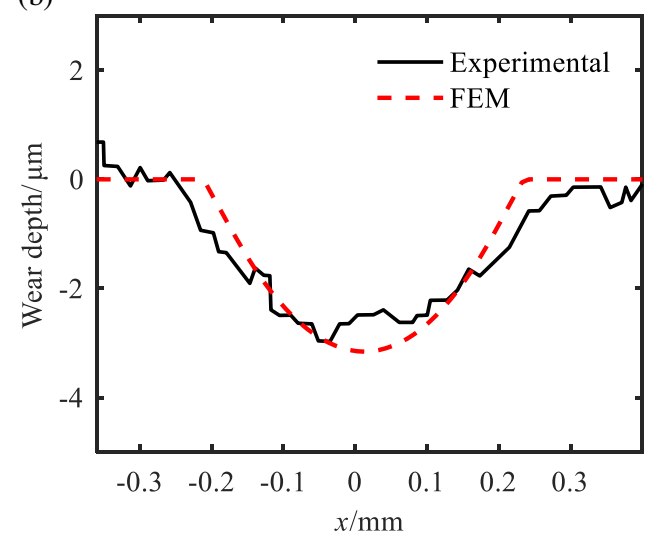

Figure 3 Validation of the model

\section{Comparison and analysis of simulation results}

\subsection{Effect of rough surface on wear}

Smooth surface, single rough surface, and rough surface models were established to explore the influence of rough surface on fretting wear. In the single rough surface model, only the lower contact surface is rough. For the rough surface model, both contact surfaces are rough. The roughness of the rough surface is $R a=0.2 \mu \mathrm{m}$. Other parameters are the same for all three models.

The distribution of contact pressure and stress of the three models are shown in Fig. 4(a)-(c), respectively. It can be found that the distribution of contact pressure is discrete in both the single rough model and the rough model and shows the largest value in the middle area. The distribution of contact pressure is continuous in the smooth model, and its maximum is at the edge of the contact area. This is because the contact surface produces stress concentration at the locations where the surface profile changes, leading to a sudden change in the contact pressure. The contact pressures of the three models are shown in Figure 4(d). It can be seen that the value of contact pressure decreases with the number of rough surfaces. The rough model has the largest contact pressure and the smooth model has the smallest contact pressure. This means the rough model has the smallest contact area and the smooth model has the largest contact area. Fig. 5(a) shows the changes in the contact area of the three models. It can be seen that the contact area is inversely proportional to the number of rough surfaces. The contact area for the smooth model is much larger than other models, and it increases in the largest speed compared to other models when the normal load is applied. In addition, the contact area constantly increases as the wear progresses.

As shown in Fig. 5(b), the value of shear stress oscillates between positive and negative values, which means that the direction of the shear stress on the asperities is not consistent. Asperities exist on rough surfaces, and their size and shape are different. The protruding asperities came into contact after the normal load was applied. At this time, some contacts are face-to-face contacts and more are side contacts. The elastic action leads to a distribution of the shear stress oscillating between positive and negative values after the load is applied. For the smooth model, there are no asperities between the surfaces. However, the direction of the shear stress is also inconsistent due to the sudden changes in the contours at both ends of the contact area and the effect of elasticity. In addition, the shear stress of the smooth model is symmetrical and its value in the middle region is zero, which indicates a partial slip state. From a macro point of view, the absolute value of the shear stress increases as the number of rough surfaces increases.

Fig. 5(c) shows the relative slip distance of the three models. It can be seen that the direction of relative slip is opposite at both ends of the contact area of the three models. The smooth model is in a mixed slip state because the middle of the contact area is sticky and the two ends have a relative slip. It can be seen from the inset that the rough model has fewer asperities with relative slip than the single rough model. This also shows that the rough model has a smaller contact area.

The contact is discontinuous when rough surfaces are present. The wear depth of the three models is shown in Fig. 5(d). It can be found that the rough model has the greatest depth of wear compared with other models. The location with the greatest depth of wear is the same as the single rough model. This is because the same fractal curve is used for all the rough surfaces, and the most prominent position of the contour is the same. The wear depth in the middle area of the smooth model is zero because it is in a mixed slip state. In this state, the shear stress and relative slip distance of the smooth model are both zero in the 
middle area. Compared with the shear stress, the relative slip distance of the three models is of smaller order of magnitude. According to the wear depth equation (6), it can be concluded that the rough model has a larger wear depth, which is consistent with the trend in Fig. 5(d).
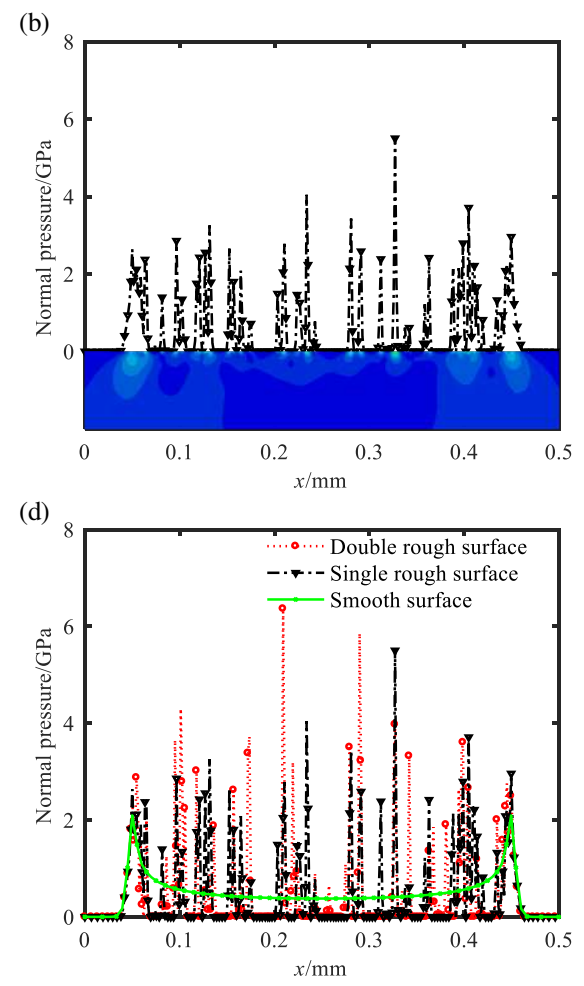

Figure 4 Comparison of contact pressure under different models
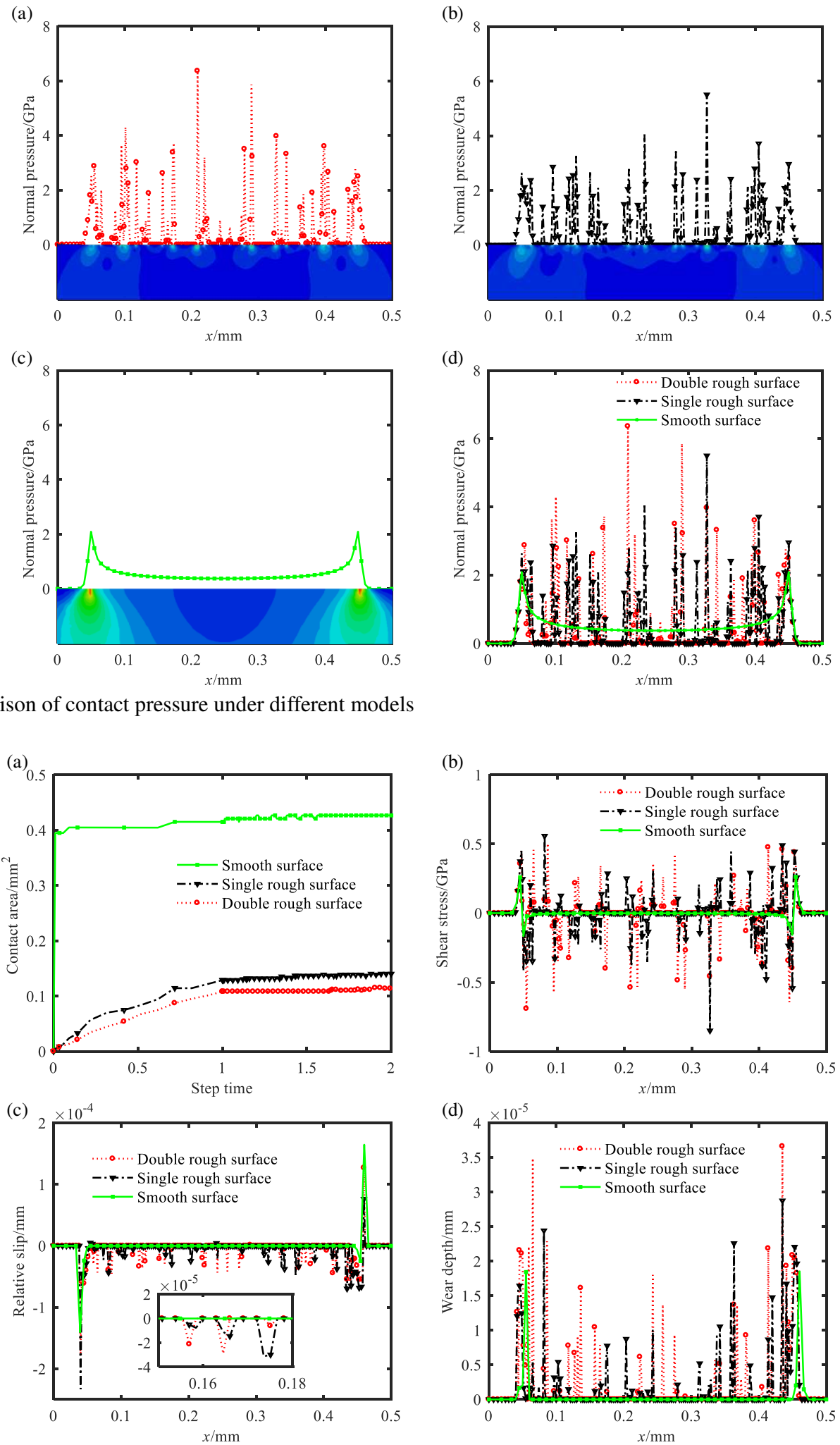

Figure 5 Wear characteristics for different models: (a) contact area; (b) shear stress; (c) relative slip; (d) wear depth 


\subsection{Effect of surface roughness on wear}

For the rough model, the roughness of the lower contact surface is fixed at $R a=0.2 \mu \mathrm{m}$. The roughness of the upper contact surface is $R a=0.2 \mu \mathrm{m}, R a=0.5 \mu \mathrm{m}$, and $R a=0.8 \mu \mathrm{m}$, and other conditions are the same. The fretting wear under different surface roughness is analyzed, as shown in Figs. 6-7.

Fig. 6(a)-(c) show the distribution of contact pressure and stress under different roughness, respectively, and the comparison of contact pressure is shown in Fig. 6(d). It can be seen that the contact pressure increases as the roughness increases. Within the same contact length, the distribution of contact pressure is denser when the roughness is smaller. This is because the asperities have different distributions in the horizontal and vertical directions under different roughness. When the roughness increases, the height difference in the vertical direction of the micro protrusions increases so that the number of the micro protrusions in contact decreases, resulting in the reduction of the contact area, as shown in Fig. 7(a). When the contact area decreases, the contact pressure increases under the same normal load.

The contact pressure becomes larger as the roughness increases. At this time, the friction coefficient does not
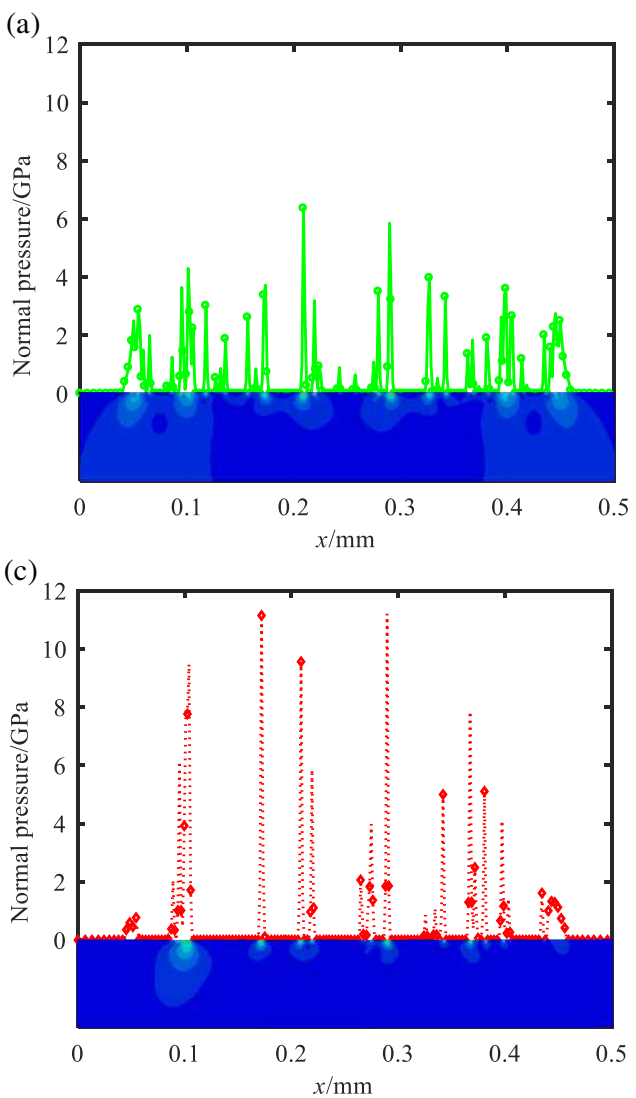

Figure 6 Comparison of contact pressure under different roughness change, then the friction between the two surfaces will become larger. Therefore, the shear stress increases under the same displacement, as shown in Fig. 7(b). Fig. 7(c) shows the relative slip distance under different surface roughness. It can be seen that the relative slip distance also increases with the increase of roughness. Compared with the middle area, the relative slip distance is larger on both sides of the contact area, demonstrating that the wear at both ends of the contact area is the most severe, exhibiting the same trend as shown in Fig. 5(d). The comparison of wear depth under different roughness is shown in Fig. 7(d). It can be seen that the wear depth increases with roughness. Compared with the middle area, the wear depth on both sides of the contact area is greater, consistent with the law of relative slip distance. The number of incremental steps $T$ does not change because the number of cycles of wear does not change. The shear stress and relative slip distance increase with the increase of roughness. Then according to the wear equation (6) of the energy model, we infer that the wear depth increases with the roughness, which is consistent with the simulation results. Therefore, the roughness between the contact surfaces of the connection structure should be reduced as much as possible to reduce the adverse effects of fretting wear.
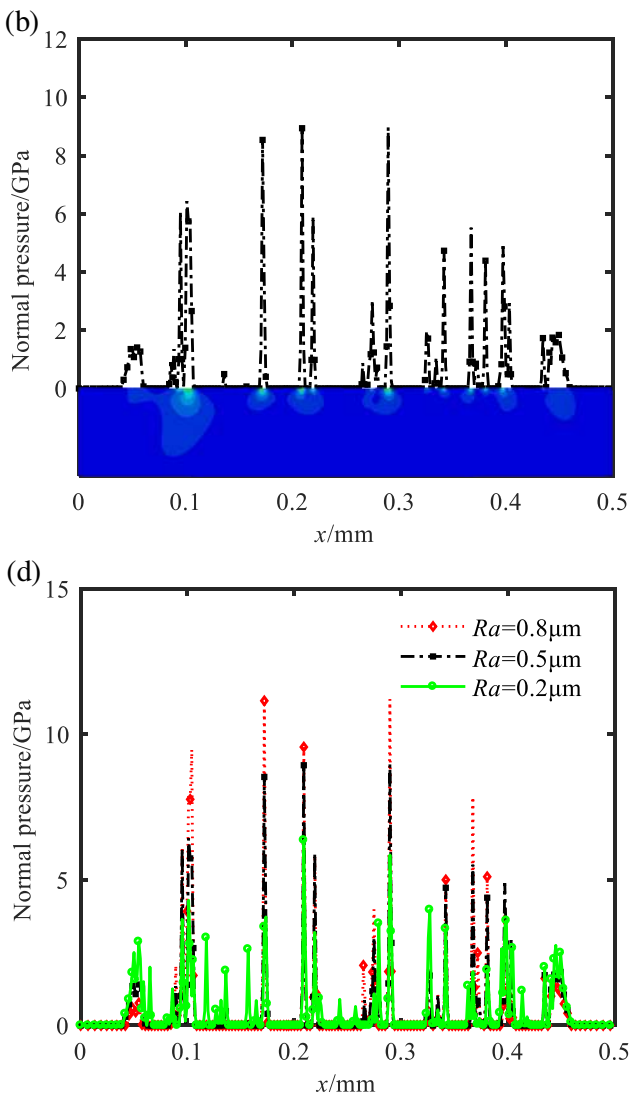

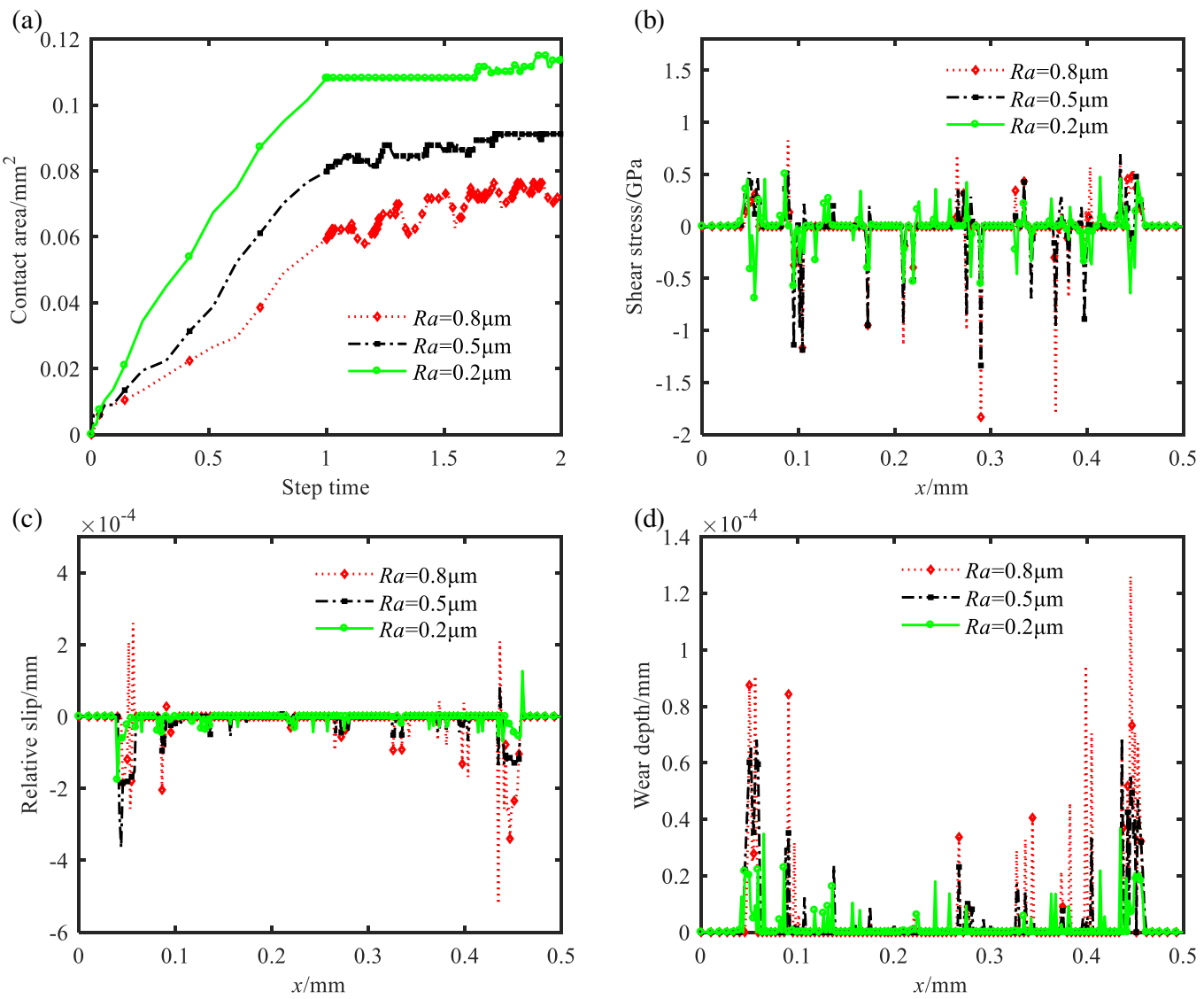

Figure 7 Wear characteristics under different roughness: (a) contact area; (b) shear stress; (c) relative slip; (d) wear depth

\subsection{Effect of materials on wear}

In addition, the effect of materials on the fretting wear is systematically studied, as shown in Figs. 8-9. The material of the lower specimen of the rough model is defined as alloy steel. The upper test pieces are defined as alloy steel, QT800-2, and HT200, respectively. Other conditions are the same.

Fig. 8(a)-(c) show the contact pressure and stress under different materials, respectively, and the comparison of contact pressure is shown in Fig. 8(d). It can be found that the contact pressure shows the same trend with the change of Young's modulus of the upper specimen material, that is, the contact pressure increases with the increase of Young's modulus. The distribution of contact pressure does not change while its magnitude varies. The relationship of the contact area over time is shown in Fig. 9(a). It can be seen that the contact area under the three materials fluctuates up and down, but the macroscopically continues to increase. Among them, HT200 has the largest contact area and alloy steel has the smallest contact area. The above phenomenon occurs because the roughness and the contact position do not change. The magnitude of Young's modulus represents the stiffness of the material, and it affects the deformability of the material. The deformability of the material decreases as the rigidity of the material increases. Therefore, the contact area decreases as the rigidity of the material increases, and the contact pressure presents the opposite trend.

Fig. 9(b) shows the relationship between the shear stress and the material. The distribution of shear stress does not change under the same rough profile, but the position of the maximum shear stress is changed. The maximum shear stress of alloy steel is near position $x=0.05$, QT800-2 is near $x=0.22$, and HT200 is near $x=0.45$. In addition, the maximum shear stress increases with Young's modulus. The change of the shear stress is due to the different resistance to deformation of the material and the change of the contact area. Materials that are more susceptible to deformation can promote the occurrence of relative slip. Therefore, the relative slip distance is the largest when the material is HT200, as shown in Fig. 9(c). The shear stress determines the size of the wear depth when the material is the same. Therefore, the wear depth is the largest when the material is alloy steel, as shown in Fig. 9(d). In practical applications, materials with a smaller Young's modulus should be selected to slow down the effect of fretting wear. 
(a)

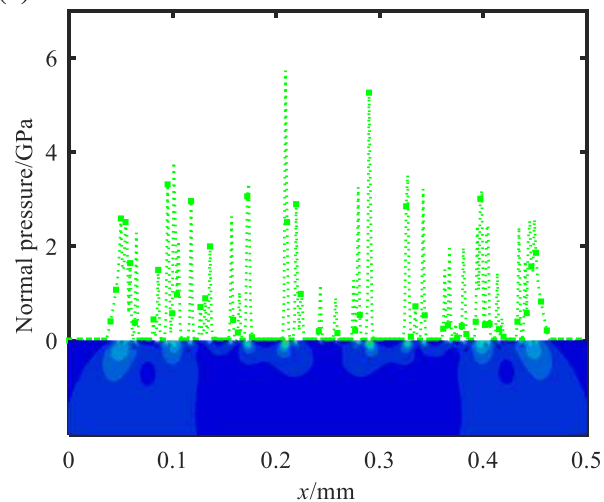

(c)

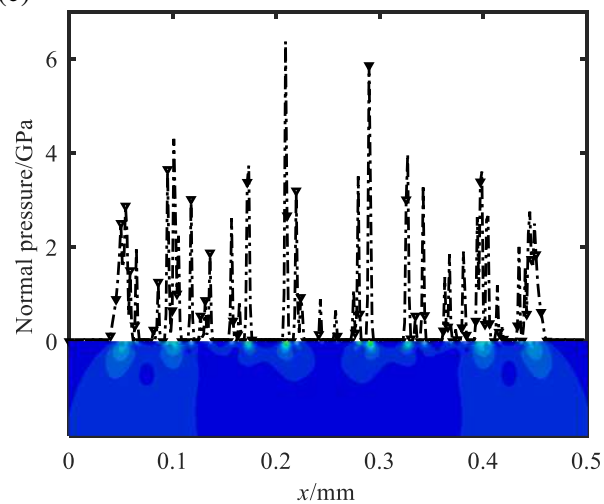

(b)

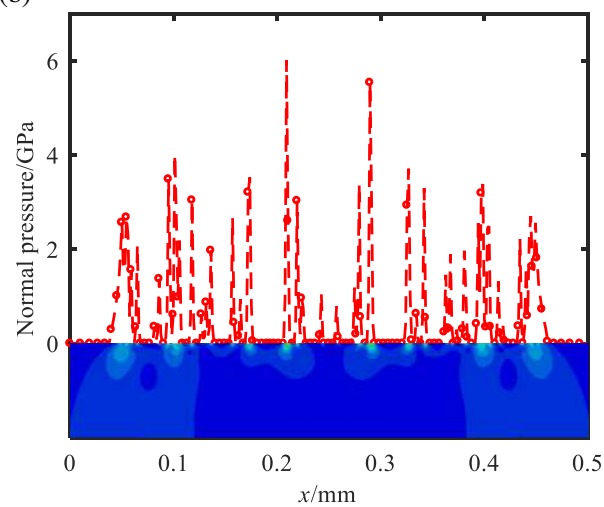

(d)

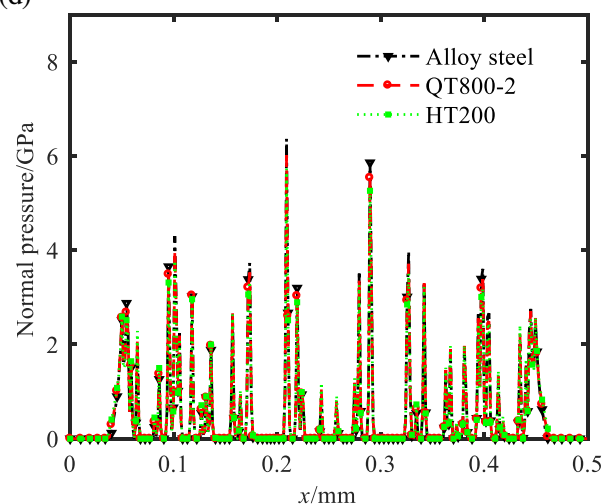

Figure 8 Comparison of contact pressure under different materials

(a)

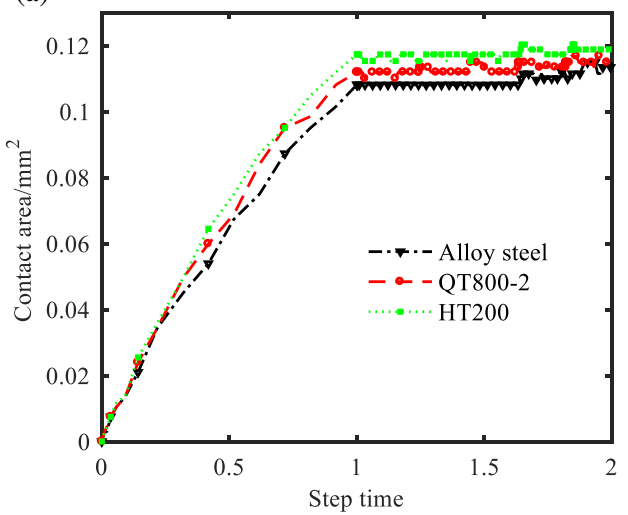

(c)

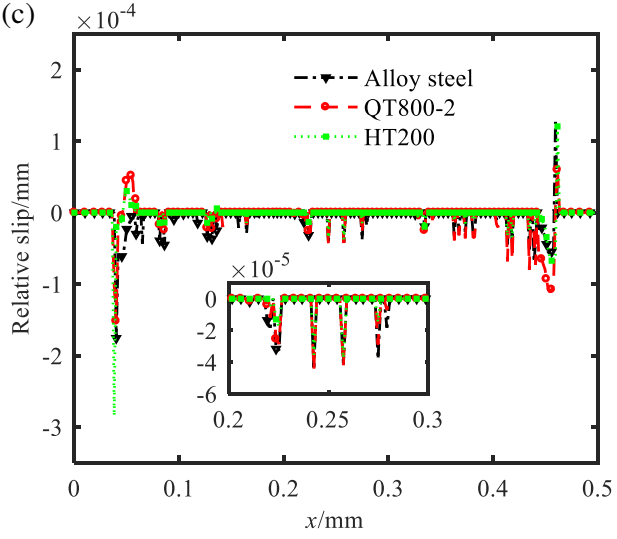

(b)

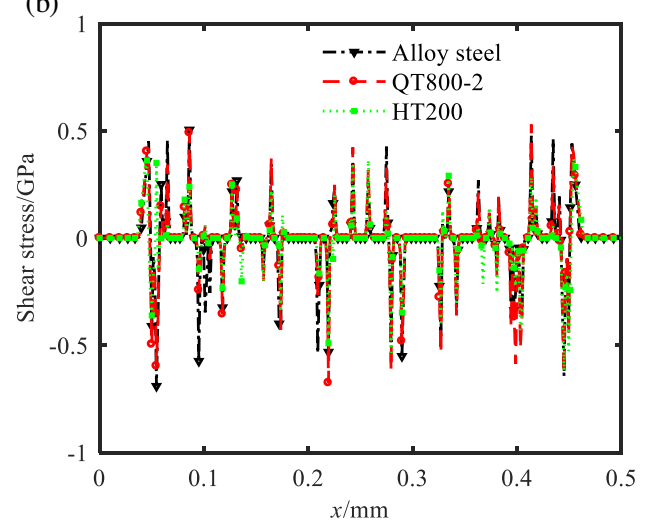

(d)

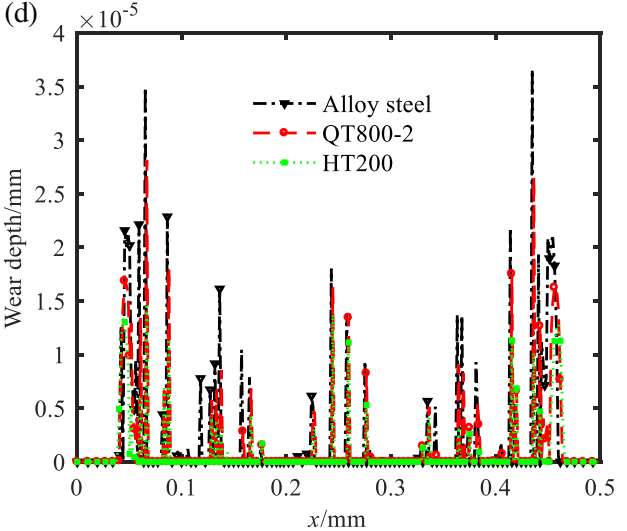

Figure 9 Wear characteristics under different materials: (a) contact area; (b) shear stress; (c) relative slip; (d) wear depth 


\subsection{Effect of the friction coefficient on wear}

The coefficient of friction is another important parameter that affects fretting wear. Here, we consider the cases for different friction coefficients of the rough model, i.e., $\mu=0.4, \mu=0.6$ and $\mu=0.8$, while other parameters regarding the roughness and material are the same. The wear under different friction coefficients is analyzed, as shown in Fig. 10 and Fig. 11.

Fig. 10(a)-(c) show the contact pressure and stress under different friction coefficients, respectively, and the comparison of contact pressure is shown in Fig. 10(d). It can be seen that the distribution of contact pressure does not change for different friction coefficients. The size of the contact pressure changes slightly with the change of the friction coefficient. We know that the rough surface is composed of many asperities of different sizes. Fretting occurs on partial, discontinuous, and contacting asperities. This makes the actual contact area very small. The contact area changes slightly with the change of the friction coefficient, as shown in Fig. 11(a). Small changes in the total contact area are allocated to each asperity. As a result, the change in the contact area of each asperity will be smaller. Therefore, the contact pressure changes little.

Fig. 11(b) shows the shear stress under different friction coefficients. It can be found that the shear stress decreases with the decrease of the friction coefficient. The location of the maximum shear stress is changed. Because the increase in the friction coefficient means that the friction between the surfaces becomes larger. As a result, some contact parts change from a slipping state to an adhesive state, and other contact parts are affected. Therefore, the change of the friction coefficient has a great influence on the shear stress.

The increase in friction prevents relative slip between two contact surfaces. Therefore, the relative slip distance decreases as the friction coefficient increases, as shown in Fig. 11(c). According to the wear depth equation (6) of the energy model, it can be known that the wear depth is reduced. Fig. 11(d) shows the wear depth under different friction coefficients, which is consistent with the theoretical results. In addition, the position of the maximum wear depth also changes with the change of the friction coefficient because the position of the maximum shear stress has changed.

(a)

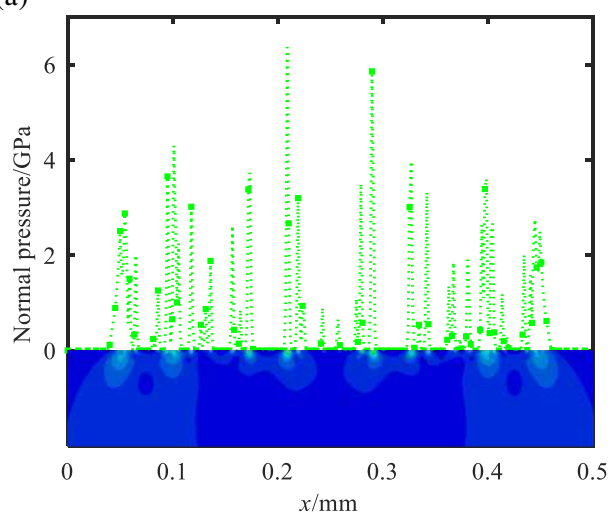

(c)

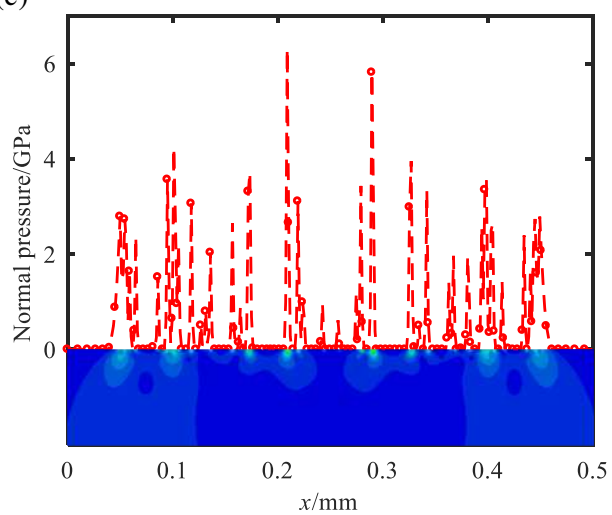

(b)

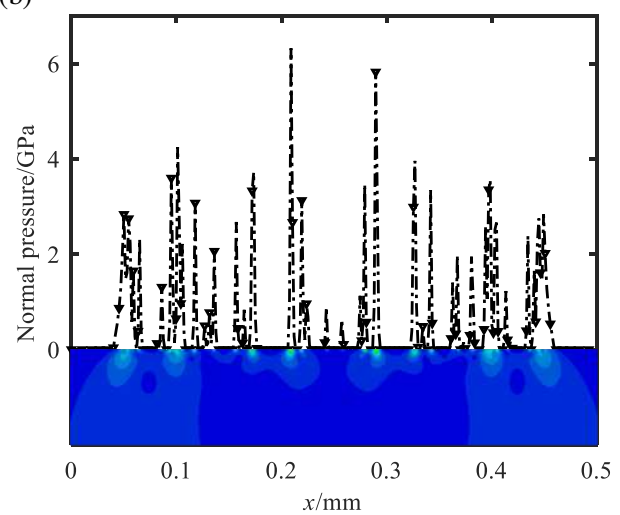

(d)

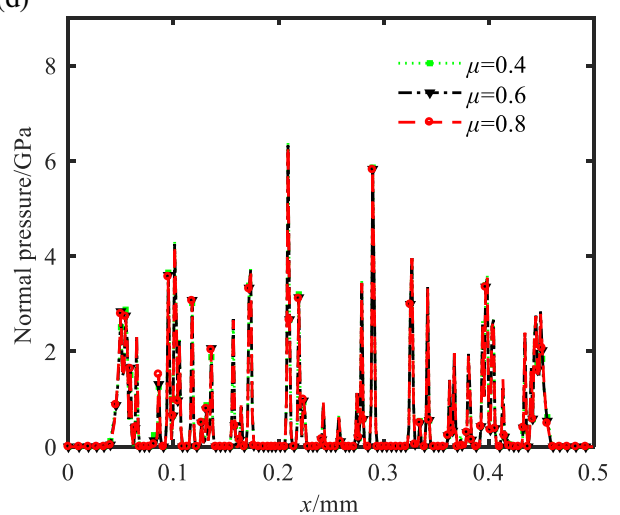

Figure 10 Comparison of contact pressure under different coefficient of friction 

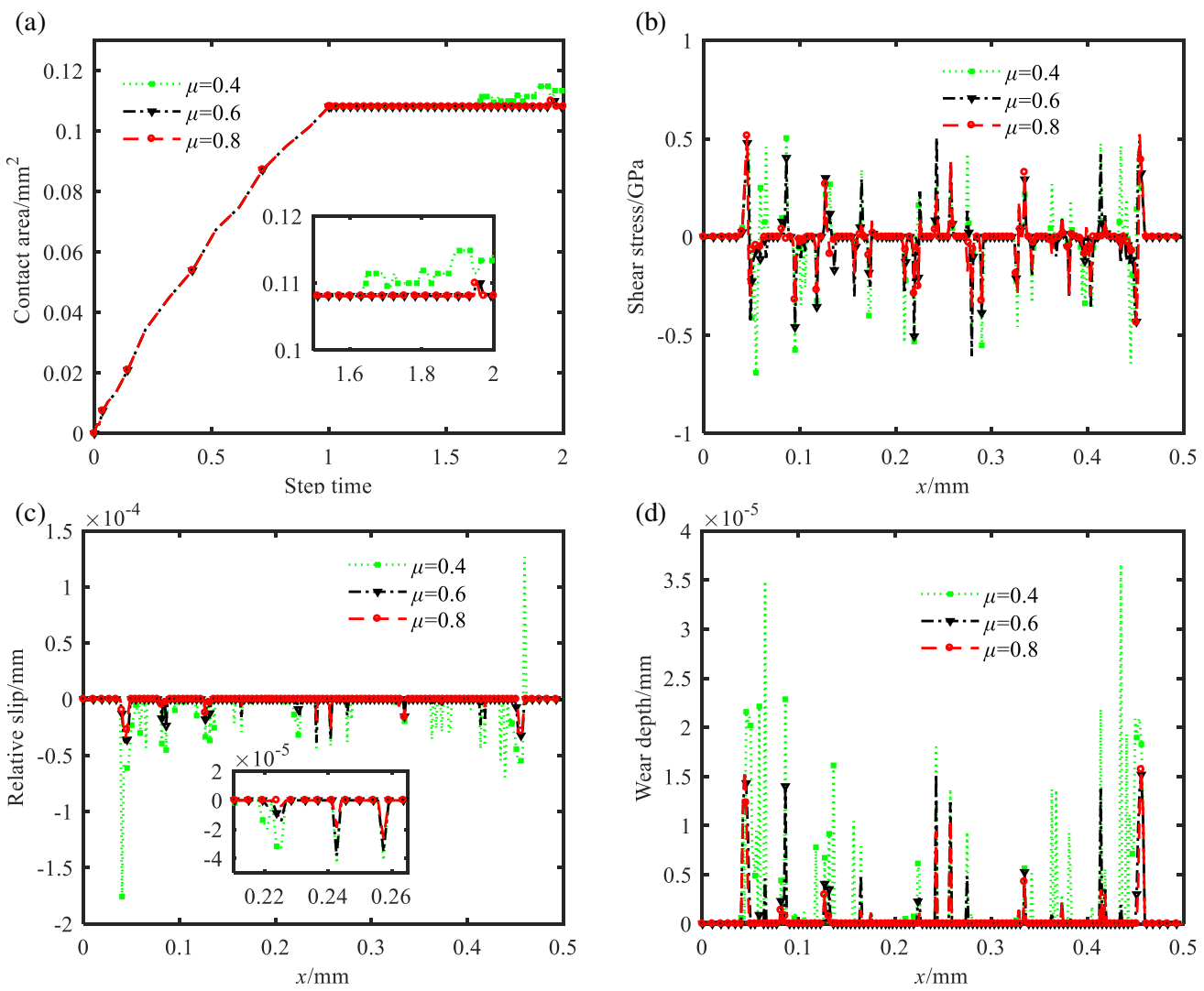

Figure 11 Wear characteristics under different coefficient of friction: (a) contact area; (b) shear stress; (c) relative slip; (d) wear depth

\section{Conclusions}

A finite element model of rough contact was developed to better study the fretting wear of mechanical connections. A fractal function is used to characterize the shape of a rough surface. The stress results of the rough surface model are compared with other models and their differences are analyzed. The influence of roughness, material parameters, and the friction coefficient on the fretting wear characteristics under rough contact is investigated. The main conclusions are as follows.

(1) The rough model can simulate real fretting wear and calculate wear more accurately. We find that the wear depth and contact pressure increase with the number of rough surfaces. However, the contact area decreases as the number of rough surfaces increases. The greater the number of rough surfaces, the less contact occurs and the distribution is more discrete.

(2) For the same material and friction coefficient, the contact pressure and wear depth increase with surface roughness. The actual contact area decreases as the surface roughness increases.

(3) For the same surface roughness and friction coefficient, the contact pressure and wear depth increase with Young's modulus. The actual contact area decreases as Young's modulus of the material increases.

(4) When the material and surface roughness are the same, the wear depth decreases as the friction coefficient increases. There is no significant change in contact pressure and actual contact area with the change of friction coefficient.

\section{Declaration}

\section{Acknowledgements}

Not applicable.

\section{Funding}

Supported by National Natural Science Foundation of China (Grant No. 51975449) and Key Research and Development Program of Shaanxi (Grant 2021GY-309)

\section{Availability of data and materials}

The datasets supporting the conclusions of this article are included within the article.

\section{Authors' contributions}


The author' contributions are as follows: LL and AC were charge of the whole trial; LL and GL wrote the manuscript and conducted the simulation model; JW and XS revised the final manuscript.

\section{Competing interests}

The authors declare no competing financial interests.

\section{Consent for publication}

Not applicable

\section{Ethics approval and consent to participate}

Not applicable

\section{References}

[1] G Li, Z Xia, Q Deng. Study on failure of several mechanical parts due to fretting. Heat Treatment, 2016, 31(04): 47-51. (in Chinese)

[2] Z Zhou, W Luo, J Liu. Recent development in fretting research. Tribology, 1997,17(03): 81-89. (in Chinese)

[3] N Fan, Y Wang, Q Wang, et al. Effects of load on fretting wear behaviors of 304 stainless steels. Tribology, 2016, 36(05): 555-561. (in Chinese)

[4] L Li, L Kang, S Ma, et al. Finite element analysis of fretting wear considering variable coefficient of friction. Proceedings of the Institution of Mechanical Engineers, Part J: Journal of Engineering Tribology, 2019, 233(5): 758-768.

[5] J F Archard. Contact and rubbing of flat surfaces. Journal of Applied Physics, 1953, 8: 981-988.

[6] I R Mccoll, J Ding, S B Leen. Finite element simulation and experimental validation of fretting wear. Wear, 2003, 256: 1114-1127.

[7] J J Madge, S B Leen, I R Mccoll, et al. Contact-evolution based prediction of fretting fatigue life: Effect of slip amplitude. Wear, 2006, 262(9): 1159-1170.

[8] A T Kasarekar, N W Bolander, F Sadeghi, et al. Modeling of fretting wear evolution in rough circular contacts in partial slip. International Journal of Mechanical Sciences, 2006, 49(6): 690-703.

[9] B D Leonard, F Sadeghi, S Shinde, et al. Rough surface and damage mechanics wear modeling using the combined finite-discrete element method. Wear, 2013, 305(1-2): 312-321.

[10] X Shen, Y Liu, L Cao, et al. Numerical Simulation of Sliding Wear for Self-lubricating Spherical Plain Bearings. Journal of Materials Research and Technology, 2012, 1: 8-12.

[11] L Tang, S Ding, H Qian, et al. Fretting fatigue tests and crack initiation analysis on zircaloy tube specimens. International Journal of Fatigue, 2014, 63: 154-161.

[12] S Fouvry, T Liskiewicz, P H Kapsa, et al. An energy description of wear mechanisms and its applications to oscillating sliding contacts. Wear, 2003, 1: 287-298.

[13] S Fouvry, P Kapsa, L Vincent. An elastic-plastic shakedown analysis of fretting wear. Wear, 2001, 1: 41-54.

[14] E Sauger, S Fouvry, L Ponsonnet, et al. Tribologically transformed structure in fretting. Wear, 2000, 245(1): 39-52.

[15] S Fouvry, P Duó, P Perruchaut. A quantitative approach of Ti-6Al-4V fretting damage: Friction, wear and crack nucleation.
Wear, 2004, 257(9-10): 916-929.

[16] K Elleuch, S Fouvry. Experimental and modelling aspects of abrasive wear of a A357 aluminium alloy under gross slip fretting conditions. Wear, 2004, 258(1): 40-49.

[17] C Paulin, S Fouvry, C Meunier. Finite element modelling of fretting wear surface evolution: Application to a Ti-6A1-4V contact. Wear, 2007, 264(1-2): 26-36.

[18] M Zhang, D Zeng, L Lu, et al. Finite element modelling and experimental validation of bolt loosening due to thread wear under transverse cyclic loading. Engineering Failure Analysis, 2019, 104: 341-353.

[19] X Jiang, F Pan, G Shao, et al. Prediction of electrical contact endurance subject to micro-slip wear using friction energy dissipation approach. Friction, 2019, 7(06): 537-550.

[20] F Svahn, Å Kassman-Rudolphi, E Wallén. The influence of surface roughness on friction and wear of machine element coatings. Wear, 2003, 254(11): 1092-1098.

[21] M Sedlaček, B Podgornik, J Vižintin. Influence of surface preparation on roughness parameters, friction and wear. Wear, 2008, 266(3): 482-487.

[22] K J Kubiak, T G Mathia, S Fouvry. Interface roughness effect on friction map under fretting contact conditions. Tribology International, 2010, 43(8): 1500-1507.

[23] K J Kubiak, T W Liskiewicz, T G Mathia. Surface morphology in engineering applications: Influence of roughness on sliding and wear in dry fretting. Tribology International, 2011, 44(11): 1427-1432.

[24] W Lu, P Zhang, X Liu, et al. Influence of surface topography on torsional fretting wear under flat-on-flat contact. Tribology International, 2017, 109: 367-372.

[25] R Singh, S N Melkote, F Hashimoto. Frictional response of precision finished surfaces in pure sliding. Wear, 2004, 258(10): 1500-1509.

[26] P Arnaud, S Fouvry. A dynamical FEA fretting wear modeling taking into account the evolution of debris layer. Wear, 2018, 412-413: 92-108

[27] W Qin, X Jin, A Kirk, et al. Effects of surface roughness on local friction and temperature distributions in a steel-on-steel fretting contact. Tribology International, 2018, 120: 350-357.

[28] K T Pereira, T Yue, M A Wahab. Multiscale analysis of the effect of roughness on fretting wear. Tribology International, 2017, 110: 222-231.

[29] C Ji, H Zhu. Research progress on M-B fractal contact model. Lubrication Engineering, 2011, 36(9): 114-119. (in Chinese)

[30] S Wang, K Komvopoulos. A fractal theory of the interfacial temperature distribution in the slow sliding regime: Part I-Elastic contact and heat transfer analysis. Journal of Tribology, 1994, 116(4): 812-822.

[31] S Wang, K Komvopoulos. A fractal theory of the interfacial temperature distribution in the slow sliding regime: Part II-Multiple domains, elastoplastic contacts and applications. Journal of Tribology, 1994, 116(4): 824-832.

[32] L Li, H Tian, Q Yun, et al. Study on temperature rise distribution of contact surface under cyclic load. Proceedings of the Institution of Mechanical Engineers, Part J: Journal of Engineering Tribology, 2021, 235(1): 138-148.

[33] J Liu, H Shen, Y Yang. Finite element implementation of a varied friction model applied to torsional fretting wear. Wear, 2014, (1-2): 220-227.

[34] R Hojjati-Talemi, M A Wahab, P D Baets. Finite element simulation 
of phase difference effects on fretting fatigue crack nucleation behaviour. Proceedings of the Institution of Mechanical Engineers, Part J: Journal of Engineering Tribology, 2014, 228(4): 470-479.

[35] T Y Yue, M A Wahab. Finite element analysis of fretting wear under variable coefficient of friction and different contact regimes. Tribology International, 2017, 107: 274-282.

[36] V Done, D Kesavan, R M Krishna, et al. Semi analytical fretting wear simulation including wear debris. Tribology International, 2017, 109: 1-9.

\section{Biographical notes}

Ling Li, born in 1981, is currently a professor and a $\mathrm{PhD}$ candidate supervisor at School of Mechanical and Electrical Engineering, Xi'an University of Architecture and Technology, China. He received his $\mathrm{PhD}$ degree from Beijing University Of Technology, China, in 2012. His research interests include mechanical dynamics, contact mechanics and tribology.

Tel: +86-15389062450; E-mail: liling@xauat.edu.cn

Gang-Hua Li, born in 1997, is currently a master candidate at School of Mechanical and Electrical Engineering, Xi'an University of Architecture and Technology, China.

E-mail: ganghuali@163.com

Jing-Jing Wang, born in 1996, is currently a $\mathrm{PhD}$ candidate at School of Mechanical and Electrical Engineering, Xi'an University of Architecture and Technology, China. He received his master degree from Xi'an University of Architecture and Technology, China, in 2021. His research interests include microscopic interface contact mechanics.

E-mail: lee_wjj@163.com

Xiao-Hui Shi, born in 1977, is currently a lecturer at Xi'an University of Architecture and Technology, China. He received his $\mathrm{PhD}$ degree from Xi'an University of Architecture and Technology, China, in 2006. His research interests include smart city transportation planning, design and system integration.

E-mail: 13811382617@163.com

An-Jiang Cai, born in 1965, is currently a professor and a PhD candidate supervisor at School of Mechanical and Electrical Engineering, Xi'an University of Architecture and Technology, China. He received his master degree from Xi'an University of Architecture and Technology, China, in 2002. His main research interests include mechanical transmission, machinemry manufacturing technology and precision machining technology.

E-mail: Cai_aj@163.com

\section{Appendix}

Appendix and supplement both mean material added at the end of a book. An appendix gives useful additional information, but even without it the rest of the book is complete: In the appendix are forty detailed charts. A supplement, bound in the book or published separately, is given for comparison, as an enhancement, to provide corrections, to present later information, and the like: A yearly supplement is issue. 